\title{
TEORIA CAUSAL DA MEMÓRIA: UMA INTRODUÇÃO EM FILOSOFIA DA MEMÓRIA
}

\author{
Glaupy Fontana Ribas ${ }^{1}$ \\ Universidade Federal de Santa Maria (UFSM) \\ https://orcid.org/0000-0001-7147-7488 \\ E-mail: fontanaribas@outlook.com
}

\begin{abstract}
RESUMO:
O presente artigo busca ser uma introdução à Teoria Causal da Memória, sendo esta uma das teorias mais amplamente discutidas em filosofia da memória nos dias atuais. O texto é iniciado com a formulação da teoria causal proposta por Martin e Deutscher, onde são apresentados os critérios propostos pelos autores para que um estado mental conte como um caso de memória, dentre eles, o famoso critério causal, que estabelece que a memória deve estar causalmente conectada com a experiência passada que a deu origem. Posteriormente é discutido se tais critérios são necessários e suficientes para a memória e são apresentadas duas teorias que adicionam outros critérios para que um estado de mental possa contar como um caso de memória, a saber, a Teoria Causal Epistêmica e a Teoria Causal Autonoética. Em seguida é introduzido o conceito de traços de memória, os quais são, segundo Martin e Deutscher, aquilo que garante a conexão causal entre a memória e a experiência passada; são apresentados o modelo de traços enquanto análogos estruturais e o modelo de traços distribuídos, bem como os problemas que advém dessas concepções de traços. Posteriormente o conceito de causalidade é discutido com mais profundidade e é apresentada a Teoria Causal Procedural, que visa escapar dos problemas acarretados pelas concepções anteriormente citadas de causalidade através de traços. Por fim, apresenta-se o Descontinuísmo, uma teoria acerca da relação entre a memória e a imaginação, a qual é uma implicação direta da adoção da Teoria Causal da Memória.
\end{abstract}

PAlAVRAS-ChAVE: Teoria Causal da Memória; Memória episódica; Traços de memória; Causalidade; Descontinuísmo.

\section{THE CAUSAL THEORY OF MEMORY: AN INTRODUCTION IN PHILOSOPHY OF MEMORY}

\begin{abstract}
:
This paper is an introduction on the Causal Theory of Memory, one of the most discussed theories in philosophy of memory in the present days. We begin with Martin \& Deutscher's formulation of the theory, in which the authors present three criteria in order for a given mental state to be considered an instance of memory, amongst them, the famous causal criterion, which stipulates that a memory must be causally connected to the past experience. Subsequently, we discuss if these criteria are necessary and sufficient for memory and we present two theories that complement these criteria with an epistemic and a phenomenological criterion, i.e., the Causal Epistemic Theory and the Causal Autonoetic Theory. We then introduce the concept of memory traces, which are, according to Martin \& Deutscher, the causal link between the memory and the past experience which created this memory; we present the model of traces as structural analogues and the model of distributed traces and discuss the problems which arise for each of these models of traces. Afterwards we focus on the concept of causality and present the Causal Procedural Theory, which offers a different conception of causality that does not focus on the memory traces, but on causal process itself. Lastly, we present the theory called Discontinuism, a theory about the relation between memory and imagination, which follows directly from the Causal Theory of Memory.
\end{abstract}

KEYWORDS: Causal Theory of Memory; Episodic memory; Memory traces; Causation; Discontinuism.

${ }^{1}$ Doutorando(a) em Filosofia na Universidade Federal de Santa Maria (UFSM), Santa Maria - RS, Brasil.

RIBAS, Glaupy Fontana. Teoria causal da memória: uma introdução em filosofia da memória. Griot : Revista de Filosofia, Amargosa-BA, v.21 n.3, p.148-163, outubro, 2021. 


\section{Introdução}

Há, em filosofia, um longo debate no qual busca-se estabelecer quais são as condições para que um estado mental possa ser considerado um caso de memória. O presente texto irá abordar esse debate, porém limitando o nosso escopo à um dos vários tipos de memória, a saber, a memória episódica ${ }^{2}$. Memórias episódicas são aquelas nas quais o sujeito lembra de eventos (ou episódios, como o nome mesmo indica) do seu passado pessoal (TULVING, 1972). Cada uma dessas memórias tem como conteúdo uma experiência que o sujeito teve de um evento passado e esse conteúdo se apresenta para o sujeito (ou é representado pelo sujeito) de um modo muito específico, que é por vezes chamado de a fenomenologia do processo de lembrar. Essa fenomenologia característica envolve, por exemplo, a percepção de que o evento em questão foi vivenciado pelo sujeito no passado (LOCKE 1690), ou o sentimento de que a experiência em questão é familiar (BROAD, 1925), ou pela sensação de intimidade que vem junto com a memória (JAMES, 1890); e é em virtude dessa fenomenologia característica que o sujeito pode perceber que o estado mental se trata de uma memória do seu próprio passado pessoal.

Diversas teorias buscam explicar a memória episódica ${ }^{3}$, porém, no presente texto, iremos limitar ainda mais o nosso escopo e colocar nosso foco em somente uma dessas teorias, a saber, a Teoria Causal da Memória, com o objetivo de apresentar com mais profundidade as contribuições dessa teoria para os debates acerca da memória episódica. Serão apresentadas as principais versões da teoria causal existentes na literatura, suas teses centrais e motivações, bem como os problemas enfrentados pela teoria e as respostas que teóricos causais oferecem para os mesmos.

A seção dois desse texto irá fazer uma apresentação da formulação contemporânea e mais disseminada da teoria causal da memória feita por Martin e Deutscher (1966), focando nas teses centrais que compõem essa teoria, a saber, os critérios de representação presente, a condição da experiência e o critério causal. Já a seção 3 aborda dois problemas cruciais para a teoria causal: em primeiro lugar, o problema de se o critério causal é necessário para a memória, onde apresentarei brevemente uma teoria que sustenta que tal critério não é necessário, isto é, a Teoria Simulacionista da Memória de Kourken Michaelian (2016); já no segundo problema, assumindose que o critério causal é necessário (o que é defendido por filósofos causalistas), coloca-se a questão de se os três critérios de Martin e Deutscher são suficientes para a memória, apresento, então, duas teorias que oferecem critérios complementares para a teoria causal: a Teoria Causal Epistêmica de Dorothea Debus (2010) e a Teoria Causal Autonoética de Stanley Klein $(2014,2015)^{4}$. Na seção 4 aprofundaremos o debate acerca daquilo que garante o vínculo causal entre a experiência e a memória, isto é, os traços de memória, a começar pela formulação dos traços presente em Martin e Deutscher e posteriormente apresentaremos a crítica de Sarah Robins (2016), que sustenta que a concepção de traços endossada atualmente pelas ciências empíricas, isto é, os traços distribuídos, é incompatível com a concepção de traços necessária para garantir o critério causal estipulado por Martin e Deutscher. A seção 5 adentra mais a fundo nas teorias acerca da causalidade e apresenta uma alternativa à concepção de causalidade via traços presente na teoria de Martin e Deutscher, a saber, a concepção da causalidade enquanto fluência do processo presente na Teoria Causal

\footnotetext{
${ }^{2}$ A memória episódica se trata, em conjunto com a memória semântica, de um dos tipos de memória declarativa. A memória semântica é a memória de conhecimentos gerais acerca do mundo, como o conhecimento de que Brasília é a capital do Brasil, ou que a Primeira Guerra Mundial teve início em 1914. Existem também as chamadas memórias implícitas, ou não declarativas, como as memórias de associação, de priming e memórias motoras, para nomear algumas. Esses tipos de memória estão, no entanto, fora do escopo deste trabalho.

${ }^{3}$ Outras teorias da memória serão mencionadas ao longo do texto, porém, somente ao passo em que elas se relacionam com os tópicos abordados pela Teoria Causal da Memória.

${ }_{4}^{4}$ Ambas as teorias foram batizadas com esses nomes por Michaelian e Robins (2018).
} 
Procedural de Denis Perrin (2018). Por fim, a seção 6 aborda uma das consequências da teoria causal da memória, isto é, o descontinuísmo a respeito da memória e da imaginação, segundo o qual, a despeito das diversas similaridades entre os estados mentais produzidos pela memória e pela imaginação, seja a nível neural ou a nível de primeira pessoa, onde as semelhanças qualitativas são inegáveis, a teoria causal da memória implica que a memória e a imaginação de eventos futuros são processos de tipos fundamentalmente diferentes, pois a memória possui um vínculo causal com um evento específico, e a imaginação não pode possuir vínculo causal com nenhum evento futuro específico.

\section{Teses centrais}

A teoria causal da memória é uma das teorias filosóficas que busca estabelecer os critérios para determinarmos se uma aparente memória episódica que o sujeito tem é, de fato, uma memória episódica genuína, ou se ela se trata de outro tipo de estado mental (advindo de outro processo cognitivo, como da imaginação $0^{5}$, por exemplo). A tese central que caracteriza qualquer versão da teoria causal da memória consiste na tese de que um estado mental só pode ser considerado uma memória genuína de um evento passado nos casos em que existe uma conexão causal entre a memória em questão e a experiência que o sujeito teve do evento representado nessa memória. Teóricos causais mantêm que é em virtude da experiência que o sujeito teve no passado, somada a essa conexão causal, que o sujeito pode ter a memória do evento em questão, no presente. Mas uma conexão causal, por si só, não é o suficiente, pois é também necessário que essa conexão causal seja de um tipo adequado; e é nesse ponto que se encontra grande parte do debate atual entre teóricos causalistas, pois ainda não há consenso sobre o que poderia ser uma conexão causal adequada entre a experiência passada e a memória.

A teoria causal da memória contemporânea surge como um esforço de Martin e Deutscher (1966) de oferecer critérios de terceira pessoa para determinar se um estado mental que se parece como uma memória da vida do sujeito se trata, realmente, de uma memória genuína. A motivação para uma teoria desse tipo reside na existência de outros processos que resultam em estados mentais que o sujeito toma, em primeira pessoa, como casos genuínos de memória, mas que, na realidade, não o são ${ }^{6}$ (como os cenários mentais criados pela imaginação, por exemplo). A teoria causal estipula então, critérios de terceira pessoa para diferenciar casos de memória de casos nãomnêmicos, critérios que se propõem a ser objetivos, independentes de uma avaliação feita pelo sujeito, em primeira pessoa, dos seus estados mentais. Nas palavras de Martin e Deutscher:

Se alguém lembra de algo [...] então os seguintes critérios devem ser cumpridos:

1. Dentro de certos limites de acurácia, ele representa essa coisa passada.

2. Se a coisa foi "pública", então ele observou o que ele agora representa. Se a coisa foi "privada", então aconteceu com ele.

3. A sua experiência passada dessa coisa foi operativa em produzir nele um estado ou sucessivos estados, o(s) qual(is) foi/foram finalmente operativo(s) em produzir a sua representação. (MARTIN E DEUTSCHER, 1966, p. 166, tradução minha).

Podemos chamar a primeira dessas condições de "critério da representação presente" e o que Martin e Deutscher querem expressar com essa condição é que lembrar de algo envolve, da

\footnotetext{
5 As semelhanças entre a memória e a imaginação serão discutidas mais amplamente na seção 6.

${ }^{6}$ As pesquisas de Elisabeth Loftus (LOFTUS e PICKRELL, 1995; LOFTUS, 2003; LOFTUS, 2005) mostram que memórias falsas podem aparecer para o sujeito como se fossem memórias genuínas, memórias nas quais o sujeito lembra de ter vivido um evento que, na verdade, não aconteceu. Disso percebe-se que, do ponto de vista de primeira pessoa, podemos nos enganar a respeito de nossas memórias.
} 
parte do sujeito, um ato que se dá no momento presente, isto é, o ato entreter em sua mente uma imagem ou uma cena (representação) do evento em questão. A segunda condição é a "condição da experiência", a qual estabelece que o evento lembrado deve ter sido vivenciado pelo sujeito; segundo essa condição não é possível, por exemplo, que eu tenha uma memória da humanidade chegando na lua, pois eu não estava presente no evento em questão ${ }^{7}$. Já o terceiro critério, o critério causal, estipula que deve haver uma conexão causal entre a experiência e a memória, pois, de acordo com esse critério, é a experiência que opera de modo a iniciar o vínculo causal, vínculo esse que culmina na representação mnêmica, isto é, na memória do evento em questão. Cada uma dessas condições é, segundo a teoria de Martin e Deutscher, necessária, e, em conjunto, elas são suficientes para caracterizar um caso de memória.

\section{Condições necessárias e suficientes para a memória}

Martin e Deutscher visam demonstrar que cada um dos três critérios propostos em sua teoria é necessário para a memória e que, em conjunto, eles são suficientes. O primeiro dos critérios serve para demarcar que o sujeito só está lembrando quando está, de uma forma ou de outra, representando o evento no presente. Ele pode estar narrando o evento, tendo imagens mentais do evento, mas deve, de algum modo, estar engajado no processo de lembrar. Esse critério exclui casos de memórias aos quais o sujeito não está tendo acesso, estipulando que só poderemos dizer que o sujeito lembra dessas memórias no momento em que ele vier a representá-las. Já o segundo critério é necessário porque situações as quais o sujeito não presenciou não podem criar memórias no sujeito, caso contrário, como Martin e Deutscher mesmo argumentam, poderíamos ter memórias dos meses que passamos no útero de nossas mães, ou ainda, ter memórias episódicas de eventos vivenciados por outras pessoas, isto é, de eventos que não vivenciamos ${ }^{8}$.

Para demonstrar a necessidade de estipularmos um critério causal, Martin e Deutscher oferecem um caso, um experimento de pensamento, que visa motivar no leitor a conclusão de que nos casos em que a conexão causal é interrompida, não podemos dizer do sujeito que ele está lembrando do evento em questão. Eis, então, o esperimento de pensamento:

Um homem que chamaremos de Kent sofreu um acidente de carro e viu detalhes particulares do mesmo, dada sua posição especial. Posteriormente, Kent sofreu outro acidente no qual ele é atingido por uma pancada forte na cabeça e, como resultado disso, ele esquece uma seção da sua própria história, incluindo o primeiro acidente. Ele não mais pode cumprir com o primeiro critério para a memória do primeiro acidente. Algum tempo depois deste segundo acidente, um hipnotizador popular e um tanto irresponsável faz um espetáculo. Ele hipnotiza um grande número de pessoas, e sugere a eles que eles acreditem que sofreram um acidente de carro em um certo local e data. $O$ hipnotizador nunca ouviu nada sobre Kent nem os detalhes de seu acidente e é por pura coincidência que o local, a data e os detalhes que ele fornece são iguais aos do primeiro acidente de Kent. A sugestão funciona e então, depois que o espetáculo termina, Kent cumpre novamente com o critério I. Ele acredita firmemente que sofreu um acidente. $O$ acidente que ele acredita ter sofrido é igual ao seu primeiro acidente em seus mínimos detalhes. Durante todo esse tempo ele satisfez o critério 2, é claro. Entretanto, mesmo que seja claro que ele satisfaz os dois

\footnotetext{
${ }^{7}$ Nesse caso eu posso ter uma memória semântica da humanidade chegando na lua , isto é, eu consigo me lembrar de informações acerca desse acontecimento, qual foi o dia em que ele ocorreu, quais pessoas estavam envolvidas, etc. Mas somente os astronautas (Neil Armstrong, Michael Collins e Buzz Aldrin) que chegaram na lua podem ter uma memória episódica do evento em questão, pois eles vivenciaram o evento em primeira mão. Sobre essa distinção, ver Klein (2015).

${ }^{8}$ Lembrando que podemos ter a memória episódica dessas pessoas nos contando sobre esses eventos, ou ter a memória episódica de nós vendo vídeos desses eventos, mas não podemos ter a memória episódica de nós mesmos vivenciando tais eventos, pelo simples fato de que os não vivenciamos.
} 
primeiros critérios, é muito duvidoso que seja o caso que ele lembre. (MARTIN E DEUTSCHER, 1966, p. 174, tradução minha).

Martin e Deutscher defendem, portanto, que Kent não está, de fato, lembrando do acidente, movidos pela ideia de que não é o acidente em questão que está gerando a memória em Kent, mas sim a hipnose; e movidos também pela ideia de que a cadeia causal entre o acidente e a aparente memória de Kent foi interrompida, já que não há ligação causal nenhuma entre a experiência que Kent teve do evento e a sugestão dada pelo hipnotizador.

Além do caso de Kent, Martin e Deutscher propõem um outro caso, o famoso Caso do Pintor, que cumpre um duplo propósito no texto. O primeiro deles é demonstrar que é possível que um indivíduo tenha uma memória de um evento passado sem a crença de que o evento em questão foi vivido por ele no passado ${ }^{9}$, e o segundo propósito é motivar ainda mais a necessidade do critério causal. Os autores escrevem:

\begin{abstract}
Suponha que alguém peça a um pintor para que ele pinte uma cena imaginária. O pintor concorda em fazê-lo e, acreditando que ele pinta uma cena puramente imaginária, ele pinta uma cena detalhada de uma fazenda, incluindo uma casa de uma certa cor e forma, várias pessoas com características detalhadas, itens particulares de roupa, etc. Seus pais então reconhecem a pintura como uma representação muito acurada de uma cena que o pintor viu somente uma vez durante a sua infância. As figuras e cores são tal como o pintor as viu somente uma fez na fazenda que ele agora retrata. Podemos adicionar mais $e$ mais evidências para forçar a conclusão de que o pintor fez sua pintura não por mero acidente. Mesmo que o pintor acredite que sua pintura é puramente imaginária e que ela não representa nenhuma cena real, os observadores maravilhados tem toda a evidência necessária para estabelecer que, de fato, ele está lembrando uma cena da sua infância. Que outra explicação poderia haver para a sua pintura ser tão igual ao que ele presenciou? (MARTIN E DEUTSCHER, 1966, p. 167, 168, grifo meu).
\end{abstract}

Os autores argumentam que a capacidade do pintor de replicar a cena com tanta exatidão só faz algum sentido se for o caso que que ele estava tendo uma memória do evento em questão, mas que, além disso, uma explicação precisa ser fornecida para o fenômeno de que a experiência passada gera uma memória no sujeito, isto é, somente dizer que o sujeito experimentou o evento no passado não fornece uma explicação de como (isto é, da causa) o sujeito lembra do evento. Uma cadeia causal que conecta a experiência e a memória é o elemento que falta para explicar como tal fenômeno é possível.

Se esses casos cumprem com o objetivo proposto, isto é, se Martin e Deutscher conseguem demonstrar a necessidade de estipularmos um critério causal, é matéria de debate em filosofia da memória, dado que a principal força dos experimentos mentais citados pelos autores reside em invocar as intuições dos indivíduos sobre esses casos e nenhum argumento ou evidência mais forte é fornecido no texto para motivar a necessidade do critério causal. Além disso, a narrativa do pintor criada pelos autores parece pressupor aquilo que eles querem provar, pois pressupõem já na construção da narrativa aquilo que querem provar com a narrativa, isto é, que uma conexão causal é necessária entre a memória e o evento. Dessa forma, os autores cometem uma petição de princípio $^{10}$.

\footnotetext{
${ }_{9}^{9}$ Os autores discutem a questão da memória sem crença em grande detalhe no seu texto, em embate à tradição da época que defendia que é característico de todas as memórias de eventos passados que elas sejam acompanhadas da crença de que esse evento ocorreu e que foi vivenciado pelo sujeito no passado.

${ }^{10}$ Que Martin e Deutscher cometem uma petição de princípio foi um um ponto trazido pelo meu colega, Guilherme Morais Corrêa, em discussões do Laboratório de Filosofia da Memória da UFSM, ele mesmo motivado pela leitura de Dorothea Debus (2010, p. 19).
} 
Demonstrar que uma conexão causal é realmente necessária para gerar os casos de memória é um dos maiores problemas enfrentados pela teoria causal no presente, pois há outras teorias que visam explicar o processo da memória assumindo que tal critério não é necessário. Em tais teorias, outros elementos são postulados como sendo necessários para qualificar um estado mental como sendo um estado de memória.

A teoria mais proeminente que defende que o critério causal não é necessário para a memória é a Teoria Simulacionista da Memória criada por Kourken Michaelian (2016), segundo a qual a memória é uma subcategoria de um processo mais amplo de simulação episódica que constrói representações, tanto de eventos passados, quanto de eventos futuros. No primeiro caso o evento simulado pode se tratar de algo que aconteceu na vida do sujeito, o qual é então chamado de memória, ou pode ser um evento possível do passado, mas que não aconteceu, tomando o nome de pensamento contrafactual. Quando o sistema simula um evento futuro, esses estados mentais são chamados de imaginação do futuro, ou ainda de prospecção. Dado que é o mesmo sistema que simula todos esses eventos e dado também que nos casos do pensamento contrafactual e da imaginação futura não é necessário que haja - e nem poderia haver - uma conexão entre o estado mental e o evento do mundo (pois esses eventos não aconteceram), Michaelian defende que essa conexão também não é necessária para os estados em que o sistema simula um evento que aconteceu no passado, ou seja, para os casos de memória. Tudo o que importa é que o sistema que simula esses eventos seja confiável e, nos casos em que simula as memórias, que produza representações acuradas desses eventos. Não é relevante para o simulacionista se a acurácia dessas representações é produzida por uma conexão causal com o passado ou por qualquer outro fator.

Por outro lado (e contrariamente a Michaelian), embora muitos concordem que os três critérios propostos por Martin e Deutscher sejam, cada um deles, necessários para a memória, há na literatura teóricos que defendem que, em conjunto, eles não são suficientes para que um estado mental possa ser considerado um caso de memória. Dentre esses autores destacam-se Dorothea Debus (2010) e Stanley Klein (2015). Debus argumenta que, para além dos três critérios propostos por Martin e Deutscher, devemos adicionar também uma Condição de Relevância Epistêmica para que um estado mental seja um caso de memória. De acordo com essa condição:

[...] para que uma experiência possa contar como um caso de memória, é necessário que a experiência relevante tenha relevância epistêmica para o sujeito quando ele forma juízos sobre seu passado; isto é, é necessário que o sujeito esteja disposto a levar a experiência em questão em conta quando ele forma juízos acerca do passado. (DEBUS, 2010, p. 21, tradução minha).

Esse critério é introduzido pela autora para excluir casos em que o sujeito tem uma representação mental de um evento, mas que ele não forma nenhum juízo a partir dessa representação (isto é, a representação não possui relevância epistêmica para o indivíduo). Debus refere-se a casos em que a pessoa não toma o evento como tendo sido vivenciado por ela (como no caso do pintor), argumentando que nesses casos não ocorrem os processos epistêmicos comumente decorrentes da memória, como o processo de confirmação de crenças que o sujeito tem sobre o passado, ou o processo de fazer com que ele reconsidere crenças que já possui, ou ainda fornecimento de algum conhecimento sobre o passado (DEBUS, 2010, p. 20, 21). Dessa forma, Debus argumenta que um estado mental que cumpre com os três critérios de Martin e Deutscher, mas que não cumpre com a condição da relevância epistêmica, não pode ser considerado um caso de memória.

Enquanto Dorothea Debus defende a necessidade de um critério epistêmico, Stanley Klein adiciona um critério fenomenológico à memória episódica. Klein defende que "a memória não é 
simplesmente o conteúdo da experiência, mas a maneira como esse conteúdo é experimentado" (KLEIN, 2015, p. 4, tradução minha), isso porque o lembrar envolve a sensação de reencontrar ou reviver mentalmente o evento passado, uma sensação que não está presente em outros estados mentais para além da memória. Klein $(2015$, p. 6) argumenta que um estado de memória deve ter, em primeiro lugar, sua origem causal no passado, mas que ele deve, além disso, ser sobre o passado, sendo que é essa condição, que ele chama de Condição de Temporalidade Subjetiva Orientada ao Passado, que faz com que um estado mental possa ser chamado de memória, pois vários outros estados mentais têm sua origem no passado (como crenças ou conhecimentos gerais, por exemplo) e mesmo assim esses estados não se tratam de casos de memória episódica.

Podemos perceber, portanto, que não somente na análise de Dorothea Debus, mas também para Stanley Klein, o pintor de Martin e Deutscher não está lembrando do episódio em questão. Isso porque ele não toma a imagem mental que ele representa como tendo acontecido no seu passado pessoal; ele não forma nenhuma crença a respeito do seu passado a partir dessa imagem (como Debus requer) e, além disso, a imagem que ele tem da cena que ele pinta não aparece para ele como pertencendo ou sendo sobre o seu passado pessoal, como Klein requer.

Dessa forma, podemos perceber que, mesmo para autores que endossam alguma versão da teoria causal da memória e que concordam que deve haver um vínculo causal entre a memória e o evento passado, é o caso que a mera conexão causal com o passado - ou até mesmo os três critérios de Martin e Deutscher - não sejam suficientes para explicar de modo completo a memória episódica.

\section{Traços de memória}

Na teoria de Martin e Deutscher, traços de memória são introduzidos como aquilo que constitui uma conexão causal adequada entre a experiência do evento em questão e a memória que o representa, sendo que o ímpeto de estabelecer o que seria uma cadeia causal adequada para a memória surge da possibilidade de cadeias causais desviantes, como os casos de reaprendizado. O reaprendizado acontece quando o sujeito forma uma memória de um evento, mas posteriormente essa memória é esquecida e, em outro momento, o sujeito toma ciência desse evento por alguma outra fonte (como um diário, o relato de um amigo, etc.) e forma novamente uma memória do evento em questão. Martin e Deutscher argumentam que, nesses casos, o sujeito não está lembrando do evento, pois, se não tivesse sido informado acerca do mesmo por uma fonte externa, ele não seria capaz de lembrar. $O$ problema reconhecido pelos autores é que existe, no entanto, uma cadeia causal entre a experiência em questão e a memória final do evento, no seguinte sentido: (1) a experiência que o sujeito tem do evento é a causa dele sujeito contar a experiência para o seu amigo e (2) o seu amigo contar de volta para o sujeito a experiência em questão é a causa da memória; dessa forma a experiência do evento está causalmente conectada com a memória do reaprendizado. Isso faz com que um critério mais forte seja necessário, para excluir casos em que há uma cadeia causal operante, mas nos quais Martin e Deutscher querem defender que o sujeito não está tendo uma memória do evento em questão ${ }^{11}$.

A solução que Martin e Deutscher adotam é adicionar a seguinte cláusula ao critério causal: "o estado ou série de estados produzidos pela experiência passada deve constituir um análogo estrutural da coisa lembrada, na medida em que ele representa acuradamente essa coisa" (MARTIN E DEUTSCHER, 1966, p. 191, tradução minha). Essa cláusula estabelece que a

\footnotetext{
11 Essa tese é um tema de disputa, pois na teoria de Michaelian (2016), por exemplo, a informação advinda do testemunho pode ser a fonte da memória e, desde que o testemunho seja acurado, ela não deixa de contar como uma memória do evento.
} 
conexão entre a experiência passada e a memória representada no presente deve ser mantida por traços de memória (os análogos estruturais) e, ao mesmo tempo, garante que seja possível explicarmos a operatividade causal da experiência passada, fornecendo uma explicação de como a memória é capaz de preservar e, posteriormente, gerar uma representação do evento vivenciado:

Essa ideia [do traço de memória] é uma parte indispensável da nossa ideia de memória.
Uma vez que aceitemos o modelo de memória devemos também aceitar algum tipo de
traço, ou análogo estrutural daquilo que foi experienciado. [...] Enquanto mantivermos
alguma teoria da memória que contenha ideias de "armazenamento" ou de "traços",
segue-se que somente podemos lembrar daquilo que nós vivenciamos, pois é pela nossa
experiência dos eventos que as memórias "entram" no armazém. (MARTIN E
DEUTSCHER, 1966, p. 189, 190, tradução minha, grifo dos autores).

Para garantir a conexão apropriada entre a experiência e a subsequente representação mnêmica Martin e Deutscher tinham em mente uma concepção muito específica de traços, de acordo com a qual eles seriam análogos estruturais da experiência. De acordo com essa concepção, os traços representam os conteúdos porque a estrutura física do traço reflete a estrutura do conteúdo que ele carrega, assim como na famosa analogia de Wittgenstein (1922), na qual as diferenças nos sulcos em um disco de vinil refletem as diferenças no som que é reproduzido. Esse análogo estrutural deve conter, dizem Martin e Deutscher, ao menos a mesma quantidade de características quanto há detalhes na memória que o sujeito tem do evento.

A ideia de análogos estruturais era amplamente disseminada na época em que Martin e Deutscher estavam escrevendo seu texto, mas ela era entendida, de modo amplo, como uma concepção acerca de representações mentais, isto é, não era somente uma concepção sobre como a memória retém informação, mas sim uma concepção sobre como a mente representa seus conteúdos (Robins, 2016). Essa ideia não é mais defendida, no entanto, pois como Bernecker (2010) argumenta, não parece haver nenhum isomorfismo entre os conteúdos que compõem a vida mental (as memórias) do sujeito de um lado, e a estrutura do mundo, do outro.

A ideia de análogos estruturais foi suplantada pelo modelo conexionista (Sutton, 1998) de redes neurais, segundo o qual a mente representa seus conteúdos através da ativação de redes de conexão entre neurônios. Nesse modelo as memórias são geradas pela ativação de padrões de conexões neurais no córtex e hipocampo, consistindo em um padrão mais ou menos similar àquele padrão que estava ativo durante a experiência passada. Em filosofia da memória esse modelo é chamado de Traços Distribuídos e ele apresenta várias vantagens quando se trata de explicar alguns dos fenômenos com quais nos deparamos quando se trata de nossas memórias, tais como o esquecimento gradual das memórias e também porque erros de memória são tão comuns.

Em se tratando do esquecimento gradual das memórias, se Martin e Deutscher estivessem certos e houvesse um traço para cada uma de nossas memórias, ou ainda uma cadeia causal isolada para cada uma de nossas memórias, o que aconteceria é que, caso esse traço/cadeia causal fosse corrompido, nós perderíamos por completo a memória relativa a esse traço, no entanto o que observa-se de fato é a perda gradual de detalhes até que mantenha-se somente o cerne (gist) dessa memória, a sua característica mais distintiva e, por fim, ocorra a perda por completo.

O modelo conexionista explica a perda gradual de detalhes nas memórias através da perda de conexões entre neurônios que participam desse traço, já que, mesmo após consolidado, um traço de memória não é permanente e imutável, conexões são adicionadas e removidas, conforme novas memórias vão sendo consolidadas nos mesmos neurônios, pois os neurônios que compõem o traço de uma memória compõem também os traços de infinitas outras, conforme essas memórias possuem conteúdos em comum. Assim podemos explicar também porque, às vezes, algumas 
memórias se misturam quando elas se referem à eventos parecidos, afinal, os traços de ambas compartilham de vários dos seus elementos e, ao longo do tempo e também em virtude da perda dos detalhes específicos de cada uma das memórias, elas vão se misturando cada vez mais (ROBINS, 2016).

Esse modelo de traços distribuídos possui também uma boa resposta ao problema da evocação de nossas memórias, algo que antes era difícil de desvendar. O problema reside em explicar como que, ao tentarmos nos lembrar de um evento, o processo de memória consegue nos "conduzir" à memória certa que estamos tentando lembrar, e não a qualquer outra, isto é, como podemos lembrar de uma memória sem antes lembrarmos qual memória estamos tentando lembrar? No entanto, não podemos apelar para a memória ao tentarmos explicar a memória, algo que aconteceria se disséssemos, por exemplo, que no processo de lembrar o sistema neural responsável pela memória lembra ou sabe qual traço corresponde a qual memória e assim ele nos conduz à memória que estamos tentando evocar.

Entretanto, alguma explicação deve ser fornecida para esse problema pois é fato que, na grande maioria das vezes em que buscamos evocar uma memória episódica, conseguimos evocar a memória certa. O modelo de traços distribuídos consegue responder ao problema da evocação da seguinte maneira: existem dicas internas e externas; exemplos de dicas externas são como quando alguém pergunta sobre o evento em questão, ou quando o sujeito vê algo similar à algum componente daquela memória e isso o faz lembrar da memória; já exemplos de dicas internas podem ser quando o sujeito tenta ativamente lembrar do evento em questão, ou quando ele está pensando ou imaginando algo que o remete ao evento passado. Qualquer dica, seja ela interna ou externa, inicia uma ativação neural, sendo que essa ativação será passada adiante através dos neurônios que estão conectados com os neurônios iniciais, de acordo com a força da conexão entre eles - ou seja, caso a conexão entre dois neurônios seja fraca, a ativação será passada para outro neurônio cuja força de conexão com o neurônio que está passando o impulso seja mais forte. Já a força de conexão entre neurônios é determinada pela frequência com que eles são ativados em conjunto; e como a dica é algo que, por si só, possui um conteúdo (a informação visual ou auditiva que é fornecida ao agente) as conexões neurais que codificam esse conteúdo irão ativar redes de neurônios que codificam conteúdos são os mais similares a esse, chegando na memória em questão (SUTTON, 1998; ROBINS, 2016). Note que esse modelo explica também porque às vezes não conseguimos evocar a memória do evento em questão e tudo o que conseguimos evocar é outra memória, de conteúdo similar àquela. Acontece que alterações nas forças de conexão entre neurônios fará com que algumas conexões se percam e sejam suplantadas por outras, sendo assim, alguns conteúdos que antes eram facilmente evocados são suplantados por outros.

\section{Problema dos traços distribuídos}

O modelo de traços distribuídos é o modelo mais defendido atualmente dentro das ciências cognitivas; entretanto, ele apresenta um grande problema para a teoria causal da memória, talvez o maior problema enfrentado pela teoria atualmente: o problema é que esse modelo e a teoria causal possuem teses que são, como salienta Sarah Robins (2016), mutuamente inconsistentes. Robins argumenta que traços distribuídos inviabilizam o critério da teoria causal de Martin e Deutscher de que deve haver uma conexão ininterrupta entre uma experiência passada específica e a memória que a representa, porque traços distribuídos implicam que não há uma cadeia causal individual para cada uma de nossas memórias. 
Os traços são armazenados como padrões de características de eventos, mas esses padrões são sobreposicionais de modo que memórias similares são misturadas em padrões que se sobrepõem. Traços individuais não deixam uma marca distintiva e duradoura na rede através da qual sua influência causal única [e distintiva] em uma representação subsequente poderia ser detectada, muito menos distinguida da influência de qualquer outro padrão distribuído. (ROBINS, 2016, p. 3008, 3009, tradução minha).

Robins argumenta que, para que o critério da conexão causal funcione, a teoria causal precisa que um traço de memória seja uma entidade discreta e isolada dos outros traços, para que então a cadeia causal de uma memória possa ser distinguida das cadeias causais das outras memórias, somente assim seria possível conectar uma memória com a experiência específica que gerou o traço e iniciou a cadeia causal. Mas isso se torna impossível quando os traços são distribuídos, porque o novo traço é consolidado em cima de padrões já existentes e ele é modificado constantemente conforme novas memórias são consolidadas nos mesmos neurônios.

Nesse novo paradigma lembrar não consiste na ativação de um traço que estava intacto desde o momento da experiência; lembrar é, por outro lado, reconstruir um padrão de ativação neural que foi modificado diversas vezes e que busca representar um evento do passado, mas que também contém informações vindas de vários outros eventos. A memória é, portanto, uma capacidade sincrônica, e não diacrônica, pois ela não retira seus conteúdos da sua conexão com o passado, pelo contrário, o conteúdo da memória é inteiramente determinado pelo estado da rede neural no momento da evocação.

Sendo assim, dada essa incompatibilidade entre o critério da conexão causal de Martin e Deutscher e os traços distribuídos, a teoria causal da memória, em sua formulação original, corre o risco de ter que ser abandonada por completo.

\section{Concepções de causalidade}

Quanto ao conceito de causalidade, apesar de este ser muito utilizado na literatura filosófica para explicar diversos fenômenos, ele é em si mesmo um conceito cuja explicação não é objeto de consenso na filosofia, havendo uma variedade de teorias que buscam explicar a causalidade partindo de diferentes compromissos ontológicos. No âmbito da filosofia da memória, não há consenso entre os teóricos causalistas sobre como ocorre a conexão causal entre a memória e a experiência passada e, desde Martin e Deutscher, diversos modelos já foram oferecidos para tentar explicar tal causação. Em Martin e Deutscher, a tese central referente à causalidade é a ideia de operatividade ou produção através do traço. Os autores afirmam que a experiência produz um estado (ou estados) no agente e que esse estado (ou série de estados) produz a representação mnêmica, isto é, o sujeito deve estar tendo a representação mnêmica porque ele vivenciou o evento no passado, e não por alguma outra razão (como ter sido hipnotizado e levado a crer que o evento ocorreu, como no exemplo de Kent citado anteriormente).

A noção de causalidade enquanto dependência contrafactual também está presente na teoria causal, pois ao determinarem no segundo critério que, para lembrar de algo, o sujeito deve ter observado ou vivenciado o evento em questão, Martin e Deutscher estabelecem que as memórias são dependentes contrafactualmente da experiência passada, isto é, que se o sujeito não tivesse experimentado o evento, ele não poderia ter a memória do mesmo. A concepção de causalidade de Martin e Deutscher é inicialmente vaga, mas, ao fim do texto, os autores se comprometem com a ideia de causalidade via traços de memória enquanto análogos estruturais, para poderem excluir casos de reaprendizado e de retenção não mnêmica, sendo esta uma concepção de causalidade bastante específica. Ou seja, essa se trata de uma concepção de 
causalidade forte, pois afirma que não é somente uma regularidade ${ }^{12}$ ou dependência contrafactual que está em questão aqui, muito pelo contrário, é o caso que existe uma dependência contrafactual porque a experiência realmente produz algo no sujeito (é operativa) e esse algo que foi causado irá, por sua vez, ser operativo no surgimento da memória.

A causalidade via traços traz problemas para a teoria causal, como vimos na seção anterior. Existem, no entanto, outras concepções de causalidade, tal como a concepção procedural, proposta por Denis Perrin, a qual descreve a concepção causal de Martin e Deutscher como contendo quatro critérios, dos quais somente os dois primeiros devem ser mantidos:

(1) $O$ critério operativo: a experiência de $e$ deve ser a causa do estado armazenado pelo sistema:

(2) $O$ critério operativo nas circunstâncias do lembrar: o estado armazenado deve ser a causa do estado mnêmico;

(3) $O$ critério do traço de memória enquanto análogo estrutural: a informação retida deve ser um análogo estrutural do [evento] $e$ experienciado. [...]

(4) O critério da cadeia causal singular: deve haver uma cadeia causal única que vai da experiência passada de e até o atual estado de memória. [...] (PERRIN, 2018, p. 36, tradução minha).

As razões de Perrin para não endossar os dois últimos critérios são aquelas discutidas na seção 4.1 desse texto, a saber, que os traços distribuídos concebido pelas ciências empíricas impossibilitam a cadeia causal singular entre a experiência e a memória, tal como era requerido pela teoria causal de Martin e Deutscher. Assim, o quarto critério não é cumprido em virtude da falsidade do terceiro critério. No entanto, ao invés de abandonar o requerimento da necessidade da noção de causalidade por completo (como Michaelian faz na teoria simulacionista), Perrin propõe uma nova concepção de causalidade.

A causalidade, tal como proposta por Perrin, se dá no processo envolvido na memória, e não nos componentes envolvidos na memória. Dessa forma, o processo de construção da percepção da experiência original (dado que a percepção é construtiva, tal como indicado pelos modelos de processamento preditivo da psicologia ${ }^{13}$ ) é causalmente conectado com o processo de construção da memória dessa experiência, no sentido de que a construção da experiência torna o processo de construção da memória mais fluente. Perrin propõe a seguinte analogia:

Vamos imaginar que você tem duas cópias do mesmo quebra-cabeça. As peças são exatamente as mesmas em número, forma e fotos em cada caixa. Obviamente, apesar da semelhança das peças, quando o sujeito monta um dos quebra-cabeças ele não usa as peças do outro. Em outros termos, as duas séries de operações construtivas se aplicam respectivamente a pedaços de representação causalmente não relacionados (mesmo que similares). Por exemplo, se você montar os dois quebra-cabeças um após o outro, você irá possivelmente ter uma performance melhor na segunda vez do que na primeira. E se você

\footnotetext{
12 Digo isso porque existe a concepção de causalidade somente enquanto regularidade. Para um processo contar como sendo causal, segundo essa teoria, é suficiente que sempre que a causa aconteça, o efeito também aconteça, sem ser necessário postular que a causa possui algum tipo de poder causal operativo que gere o acontecimento do efeito. "O principal propósito de uma teoria da causalidade enquanto regularidade é identificar quais estruturas da natureza tornam razoável que as pessoas acreditem em causalidade mesmo que a causalidade não seja um componente da realidade fundamental. De acordo com o teórico que defende a regularidade, a conversa sobre relações causa e efeito serve como um discurso conveniente sobre como eventos do universo acabam sendo arquitetados, mas não se refere a nenhum tipo de entidade que junte ou cimente esses eventos." (KUTACH, 2014, p. 24, tradução minha, grifo meu).

${ }^{13}$ Nas teorias de processamento preditivo o que ocorre no momento da percepção é uma predição na qual o cérebro combina a informação sensorial que vem dos sentidos com nossas crenças a respeito do mundo; assim o cérebro forma uma simulação a respeito do que seria a causa desses inputs sensoriais - os objetos do mundo. A percepção sensorial seria, portanto, construída a partir de mais de uma fonte de informação.
} 
repetir as operações ainda mais, a melhoria ficará ainda mais clara. Então, possivelmente, uma série anterior de operações construtivas pode melhorar as operações de uma série posterior, mesmo que os conjuntos de peças manipuladas sejam distintos e causalmente não relacionados. (PERRIN, 2018, p. 37, tradução minha).

Dessa forma, Perrin escapa do problema enfrentado pelos traços distribuídos, já que a sua teoria não necessita que as "peças", isto é, os traços ou populações neuronais, sejam idênticos àqueles que codificaram a experiência original, ela requer somente que o processo de construção da memória seja mais fluente em virtude de que um processo construtivo similar ter acontecido durante a experiência. É nesse sentido que haveria então, um vínculo causal entre a experiência e a memória na Teoria Causal Procedural de Perrin.

\section{Memória e imaginação: descontinuísmo}

Existe em filosofia um debate antigo sobre a relação entre a memória e a imaginação, dado que ambas são muito similares em termos do seu aspecto qualitativo que experimentamos em primeira pessoa: ambas envolvem imagens mentais, ambas constroem cenários utilizando-se de elementos que já encontramos antes em nossas vidas, ambas podem trazer ao sujeito uma carga emocional positiva ou negativa, dependendo do que a cena representa, etc. Portanto, é natural que coloque-se a questão de qual seria a relação entre a memória e a imaginação.

Teóricos causalistas mantém que memória e imaginação são estados mentais de tipos diferentes e que o critério causal é aquilo que diferencia memórias de imaginações. Os conteúdos mentais que representam um episódio do passado podem ser gerados, tanto pela memória, quanto pela imaginação pois, assim como podemos lembrar do nosso passado da forma como ele ocorreu, podemos também imaginar o nosso passado de um modo diferente de como ele ocorreu, algo que é chamado de pensamento contrafactual. A diferença entre esses dois casos seria, portanto, a conexão causal com o evento ocorrido, algo que a memória tem e que o pensamento contrafactual - segundo o teórico causalista - não pode ter.

A fenomenologia do lembrar é tão parecida com a fenomenologia do imaginar, no entanto, que acontece regularmente em nossas vidas o caso de termos uma imagem mental e entrarmos em dúvida, sem conseguir saber se aquilo de fato aconteceu ou se estamos imaginando (se é uma memória genuína ou se sonhamos, por exemplo). É inegável que casos em que o indivíduo não sabe se está lembrando ou imaginando só são possíveis porque há uma similaridade enorme entre estados de memória e da imaginação, há uma similaridade no conteúdo que é representado - cenas que representam acontecimentos reais ou possíveis na vida do sujeito - e também na fenomenologia desses estados mentais, uma fenomenologia que é caracterizada por um viagem mental no tempo subjetivo (mental time travel), na qual o sujeito "desliga-se" do tempo presente e se transporta mentalmente, tanto para o futuro, quanto para o passado, se engajando na cena que está ocorrendo em sua mente (TULVING, 2001).

Caso o funcionamento das memórias (ou da mente, em geral) fosse sempre transparente para o sujeito, essa dúvida não ocorreria, seria sempre possível determinarmos em primeira pessoa se a cena que está sendo representada advém da memória ou da imaginação. Martin e Deutscher defendem que esse não é caso e que o sujeito pode estar lembrando sem crer que está lembrando ${ }^{14}$ (como no caso do pintor) e é necessário, portanto, encontrar um fator que está presente nos casos

\footnotetext{
${ }^{14}$ É também é possível que o sujeito esteja imaginando, mas que ele creia que está lembrando, como em pacientes que sofrem de alguma doença que gera confabulações (memórias falsas), tal como a Síndrome de Korsakoff (SCHNIDER 2017). Ou nos casos de implantação de memórias falsas feitos por Elizabeth Loftus (LOFTUS e PICKRELL, 1995).
} 
de memória e ausente nos casos da imaginação. Causalistas defendem que este fator é a conexão causal com o passado.

Tendo em vista essa enorme similaridade experiencial entre a memória e a imaginação, há aqueles que, contrariamente aos causalistas, defendem que elas se tratam do mesmo tipo de capacidade mental e que a única diferença entre ambas é a direção temporal para qual os estados mentais resultantes são voltados. O Continuísmo em mental time travel é a teoria na qual defendese que a diferença entre a memória e a imaginação é uma diferença de grau, e não de tipo (cf. PERRIN e MICHAELIAN, 2017). Mas a motivação para o continuísmo não reside somente nas semelhanças experienciais ou qualitativas da memória e da imaginação, mas também em evidências empíricas de que, tanto a memória, quanto a imaginação episódica do futuro, são frutos do mesmo sistema de simulação de episódios, ou seja, ambas as capacidades são geradas pelas mesmas áreas neurais (OKUDA et al.,2003).

A resposta tradicional contra o continuísmo, que já estava presente em Martin e Deutscher, é sustentar que, no caso da memória, mas não da imaginação, há uma conexão causal com o evento do passado. Dessa forma, como há um fator que está presente na memória, mas não na imaginação, não pode ser o caso que a memória e a imaginação sejam estados do mesmo tipo. Dorothea Debus (2014) vai além e argumenta que a imaginação de eventos do futuro não pode conter tal conexão causal pois é impossível que exista uma conexão com um evento que ainda não aconteceu e que talvez nunca virá a acontecer; eventos futuros são meramente possíveis, em oposição a eventos do passado que são, em termos técnicos, atuais, isto é, eles de fato aconteceram. Aquilo que a memória produz é uma representação de um evento que aconteceu na vida do sujeito, dessa forma, cada memória é gerada por um evento específico (e atual, não meramente possível) do passado, já a imaginação do futuro não possui origem em nenhum evento específico, o vínculo causal é, portanto, impossível. Nisso reside a diferença entre a memória e a imaginação que faz com que os teóricos descontinuístas sustentem que a memória e a imaginação são estados que possuem uma diferença de tipo e não de grau, sendo este o cerne da posição descontinuísta em metafísica da memória.

A posição descontinuísta é uma derivação direta da teoria causal da memória, pois ela baseia-se na tese central da teoria causal de que cada memória está conectada causalmente com um evento específico do passado do sujeito. No, entanto, como vimos nas seções anteriores, existem razões para não aceitarmos prontamente essa tese, pois, como Robins (2016) argumenta, ela pode estar em desacordo com a melhor ciência que temos disponível, a qual diz que os traços são distribuídos e que não haveria uma conexão causal singular para cada memória. Mas vimos também que é possível adotarmos concepções alternativas de conexão causal (como a concepção procedural), sendo possível salvar a ideia de que há uma conexão causal entre cada memória e a respectiva experiência que a gerou. Se esse for o caso, podemos ainda buscar defender, tanto a teoria causal da memória, quanto o descontinuísmo, em filosofia da memória.

\section{Conclusão}

O propósito desse texto era apresentar ao leitor a Teoria Causal da Memória, introduzindo os seus principais conceitos, teses e problemas. $O$ texto foi iniciado com a apresentação dos três critérios centrais (o critério da representação presente, o critério da experiência e o critério causal) da teoria causal de Martin e Deutscher, e, na seção seguinte, discutiu-se se esses critérios são, em primeiro lugar, necessários e, em segundo lugar, suficientes para explicar a memória episódica; nessa seção foram brevemente introduzidas duas teorias causais nas quais julgam-se que os critérios de Martin e Deutscher, apesar de necessários, não seriam suficientes para explicar a 
memória episódica; tais teorias buscam complementar a teoria causal clássica com outros critérios, um deles epistêmico e o outro fenomênico.

A seção seguinte foi dedicada a um dos conceitos centrais para a teoria causal, a saber, o conceito de traço de memória, e foram apresentados os dois principais modelos de traços: o modelo de traços enquanto análogos estruturais e o modelo de traços distribuídos, para então ser discutido o problema que a concepção de traços análogos enfrenta por si só, bem como a incompatibilidade do modelo de traços distribuídos com a teoria causal da memória tal como formulada por Martin e Deutscher.

Posteriormente foi discutida a concepção de causalidade que está implicada na teoria de Martin e Deutscher e foi oferecida uma concepção alternativa de causalidade mnêmica, encontrada na Teoria Causal Procedural, a qual busca evitar os problemas causados pela noção de causalidade envolvendo traços de memória. Por fim, foi apresentada uma consequência de endossarmos a teoria causal da memória, a saber, que dela segue-se o descontinuísmo a respeito da relação entre a memória e a imaginação; nessa teoria defende-se que a memória de eventos passados e a imaginação de eventos futuros são tipos fundamentalmente diferentes de estados mentais, apesar das suas diversas similaridades neurais e qualitativas.

Resta salientar que esse texto não tem o propósito de ser uma introdução exaustiva de todas as vertentes, teses e problemas envolvidos na teoria causal da memória, pois o debate acerca da memória episódica em filosofia atinge seu ápice no presente momento e, dessa forma, há ainda autores e versões da teoria causal que tiveram que ser deixados de fora desse texto, tendo em vista o propósito de não permitir que o texto se tornasse extenuantemente longo. ${ }^{15}$

\footnotetext{
${ }^{15}$ Agradecimentos: Sou imensamente grata ao meu orientador, o professor Dr. César Schirmer dos Santos, pelo seu constante estímulo para que nós, seus estudantes, consigamos ao máximo ler, discutir e escrever filosofia. Não é exagero dizer que, sem a sua instigação, eu talvez nem mesmo tivesse começado a escrever esse artigo. Agradeço também ao meu caro colega Guilherme Morais Corrêa - que conhece o texto de Martin e Deutscher com muito mais perícia do que eu jamais me atreveria a dizer de mim mesma - por apontar, a partir da leitura de Dorothea Debus, que Martin e Deutscher cometem a petição de princípio mencionada por mim nesse texto.
} 


\section{Referências}

BERNECKER, Sven. Memory: A Philosophical Study, Nova York: Oxford University Press, 2010.

BROAD, Charlie Dunbar. The Mind and Its Place in Nature. London: Routledge, 1925.

DEBUS, Dorothea. Accounting for epistemic relevance: A new problem for the causal theory of memory. American Philosophical Quarterly, v.47, n.1, p.17-29, 2010.

DEBUS, Dorothea. 'Mental Time Travel': Remembering the Past, Imagining the Future, and the Particularity of Events. Review of Philosophy and Psychology, v.5, n.3, p.333-350, 2014. JAMES, William. The Principles of Psychology. London: Macmillan, 1890.

KLEIN, Stanley. Autonoesis and belief in a personal past: An evolutionary theory of episodic memory indices. Review of Philosophy and Psychology, v.5, n.3, p. 427-447, 2014.

KLEIN, Stanley. What Memory Is. Wiley Interdisciplinary Reviews: Cognitive Science, v.6, n.1, p.1-38, 2015.

KUTACH, Douglas. Causation. Cambridge: Polity Press, 2014.

LOCKE, John. Essay Concerning Human Understanding, Peter. H. Nidditch (ed.). Oxford: Clarendon, 1975.

LOFTUS, Elizabeth; PICKRELL, Jacqueline. The formation of false memories. Psychiatric Annals, v.25, n.12, p.720-725, 1995.

LOFTUS, Elizabeth. Our changeable memories: Legal and practical implications. Nature reviews Neuroscience, v.4, n.3, p. 231-234, 2003.

LOFTUS, Elizabeth. Searching for the neurobiology of the misinformation effect. Learning \& Memory, v.12, n.1, p.1-2, 2005.

MARTIN, Charles Burton; DEUTSCHER, Max. Remembering. Philosophical Review, v.75, n.2, p.161-196, 1966.

MICHAELIAN, Kouken. Mental time travel: episodic memory and our knowledge of the personal past. Cambridge: The MIT Press, 2016.

OKUDA, Jiro. et al. Thinking of the future and the past: the roles of the frontal pole and the medial temporal lobes. Neuroimage, v.19, n.4, p.1369-1380, 2003.

ROBINS, Sarah; MICHAELIAN, Kourken. Beyond the causal theory? Fifty years after Martin and Deutscher. In: MICHAELIAN, Kourken; DEBUS, Dorothea; PERRIN, Denis (Org.) New Directions in the Philosophy of Memory. Londres: Routledge, 2018. p. 13-32.

PERRIN, Denis, A case for procedural causality in episodic recollection. In: MICHAELIAN, Kourken; DEBUS, Dorothea; PERRIN, Denis (Org.) New Directions in the Philosophy of Memory. Londres: Routledge, 2018. p. 33-51.

PERRIN, Denis; KOURKEN Michaelian. 2017. "Memory as Mental Time Travel." In: BERNECKER, Sven; MICHAELIAN, Kourken (Ed). The Routledge Handbook of Philosophy of Memory. Londres: Routledge, 2017. p.228-39.

ROBINS, Sarah. Representing the Past: Memory Traces and the Causal Theory of Memory. Philosophical Studies, v.173, n.11, p.2993-3013, 2016.

ROBINS, Sarah. Memory Traces. In: BERNECKER, Sven; MICHAELIAN, Kourken (Org.)

The Routledge Handbook of Philosophy of Memory. Londres: Routledge, 2017. p.76-87.

SCHINER, Armin, The Confabulating Mind: How the brain creates reality. Oxford: Oxford University Press, 2017.

SUTTON, John. Philosophy and memory traces: Descartes to connectionism. Cambridge: Cambridge University Press, 1998. 
TULVING, Endel. Episodic and semantic memory. In TULVING, Endel; DONALDSON, Wayne. (Org.). Organization of memory. Nova York: Academic Press, 1972. p. 381-403.

TULVING, Endel. Origin of autonoesis in episodic memory. In: ROEDIGER, Henri L. (et al.) (Org). The nature of remembering: essays in honor of Robert G. Crowner. Washington: American Psychological Association, 2001. p. 17-34.

WITTGENSTEIN, Ludwig. Tractatus Logico-Philosophicus. London: Routledge \& Kegan Paul, 1922.

Autor(a) para correspondência / Corresponding author: Glaupy Fontana Ribas. fontanaribas@outlook.com 